\title{
Emotion Regulation as a Scientific Construct: Methodological Challenges and Directions for Child Development Research
}

\author{
Pamela M. Cole, Sarah E. Martin, and Tracy A. Dennis
}

\begin{abstract}
Emotion regulation has emerged as a popular topic, but there is doubt about its viability as a scientific construct. This article identifies conceptual and methodological challenges in this area of study and describes exemplar studies that provide a substantive basis for inferring emotion regulation. On the basis of those studies, 4 methods are described that provide compelling evidence for emotion regulation: independent measurement of activated emotion and purported regulatory processes; analysis of temporal relations; measurement across contrasting conditions; and multiple, convergent measures. By offering this perspective, this article aims to engage thoughtful debate and critical analysis, with the goal of increasing methodological rigor and advancing an understanding of emotion regulation as a scientific construct.
\end{abstract}

The concept of emotion regulation has become popular in the psychological literature. In the study of child development, for example, the topic has been the subject of several books (Bradley, 2000; Eisenberg \& Fabes, 1992; Fox, 1994; Garber \& Dodge, 1991; Schore, 1994) and special sections of journals (Dodge, 1989; Eisenberg \& Moore, 1997; Stifter, 2002). Searches of the general literature reveal hundreds of diverse studies that either used the term directly (i.e., referred to emotion regulation or related terms such as emotional control, affect regulation, emotion management) or indirectly (e.g., interpreted findings in terms of emotion regulation). These studies vary in a broad range of ways. Some focus on how emotions regulate other psychological processes (e.g., degrade a cognitive operation) and others focus on individual differences in emotional self-regulation. Some treat emotion regulation as a trait (e.g., the well-regulated person); others treat it as a transitory state change (e.g., moment-to-moment adjustments in emotion). The literature also examines emotion regulation in diverse contexts, from the intimacies of close relationships (e.g., Field, 1994; Gottman, 1994) to public behavior in the athletic arena and workplace (Fisher \& Ashkanasy, 2000; Grandey, 2000;

Pamela M. Cole, Department of Psychology, The Pennsylvania State University; Sarah E. Martin, E. P. Bradley Hospital, Brown Medical School; Tracy A. Dennis, Hunter College, City University of New York.

We thank Laureen Teti and Jennifer Lynch for early contributions to the literature searches. We also thank Stephanie Shields, Crystal Wiggins Newman, and our excellent anonymous reviewers for their thought-provoking comments.

Correspondence concerning this article should be addressed to Pamela M. Cole, Pennsylvania State University, 417 Moore Building, University Park, PA 16802. Electronic mail may be sent to pmc5@psu.edu.
Hanin, 2000). In the developmental literature, studies of emotion regulation span infancy and toddlerhood (e.g., Field, 1994; Grolnick, Bridges, \& Connell, 1996), childhood (Eisenberg, 2001; Shields \& Cicchetti, 1997), adolescence (e.g., Kobak, Cole, FerenzGillies, \& Fleming, 1993; Zimmerman, 1999), and adulthood (e.g., Carstensen \& Charles, 1998; Magai \& Cohen, 1998)

The broad popularity of the concept of emotion regulation, however, co-exists with concern about its status as a scientific construct. The concept has been applied to such a range of diverse phenomena that its utility as a construct has been questioned (e.g., Cicchetti, Ackerman, \& Izard, 1995; Gross, 1998; Kagan, 1994; Rutter, 1991; Stansbury \& Gunnar, 1994; Underwood, 1997). Thus, there is enthusiastic pursuit of a construct called emotion regulation but cautious concern about whether it is a viable construct. Researchers interested in the development of emotion regulation, then, are at an important crossroads: Pursue the idea despite the cautions and challenges or abandon it as a diffuse, overinclusive, poorly defined notion.

So why pursue the study of emotion regulation? What does it offer that cannot be achieved through studying other aspects of children's emotional development? It offers a unique perspective that differs from those offered by studies of emotion expression, emotion language, and emotion understanding. The construct of emotion regulation proposes to account for how and why emotions organize or facilitate other psychological processes (e.g., focus attention, promote problem solving, support relationships) and yet why they can have detrimental effects (e.g.,

(C) 2004 by the Society for Research in Child Development, Inc. All rights reserved. 0009-3920/2004/7502-0002 
disrupt attention, interfere with problem solving, harm relationships). The concept of emotion regulation has appeal in child development research because of its role in integrating an understanding of typical and atypical development (Cole, Michel, \& Teti, 1994; Denham, 1998; Eisenberg, 2001; Keenan, 2000; Saarni, 1999).

Unfortunately, the child development literature might lead a new reader to conclude that the valence of an emotion is the sufficient ingredient for predicting outcomes. Negative emotions could be construed as culprits that disorganize functioning. Conversely, positive emotions could be construed as singularly important to successful developmental outcomes. This is an overly simplistic view. The value of the concept of emotion regulation is as a tool to understand how emotions organize attention and activity and facilitate strategic, persistent, or powerful actions to overcome obstacles, solve problems, and maintain well-being at the same time as they may impair reasoning and planning, complicate and compromise interpersonal interactions and relationships, and endanger health (Cole, Michel, et al., 1994; Gross \& Munoz, 1995). It is not the valence of an emotion but the complex processes by which emotions relate to cognition and behavior and ultimately developmental outcomes that must be conceptualized and studied. The concept of emotion regulation serves this purpose.

In stating the importance of emotion regulation, we do not intend to convey that it takes priority over other domains of psychological development, such as cognition, perception, or social relations. Rather, any psychological account of child development is incomplete without understanding the importance of emotions as motivators. They infuse experience with meaning. Certain aspects of cognition allow us to calculate the distance between the chair and the door. Emotion allows us to evaluate steadily and quickly whether it is in our interest to stay in the chair and to act instantly if we need to escape through the door. Emotion regulation helps us stay in the chair even when we feel compelled to escape.

Enthusiastic popularity does not address doubts and concerns about the value of emotion regulation as a scientific construct. Instead, such enthusiasm only increases the need for the highest scientific standards in the research enterprise. Despite the germinal works on the topic (e.g., Fox, 1994), research designs in emotion regulation have been limited in their scientific rigor and clarity. Our reading of the current child development literature generated three major concerns. First, most studies of emotion regulation use the term without definition.
Second, most studies employ methods that fail to distinguish between emotion and emotion regulation. Third, most studies interpret relations between the valence of emotion (positive or negative) and a factor of interest (e.g., adjustment) as providing information about emotion regulation without supplying evidence of any regulatory process. Future studies must pay careful attention to definition and method to provide substantive evidence for the regulating and regulated aspects of emotions.

In this article we address some of the challenges researchers face in distinguishing emotion regulation from emotion. We draw on works on emotion theory and emotion regulation to state the working definitions that we have adopted to guide our research. We then present selected examples, from the child development literature, of studies that produced substantial inferential evidence of emotion regulation. Based on these works, we summarize four methods that these studies used to provide such compelling evidence. We have not solved all the thorny issues involved in this enterprise, nor do we intend to convey that our approaches are the only methods that can be used to study emotion regulation. Our presentation is intended to highlight some of the salient problems in this area of study and to demonstrate that they can be overcome despite significant challenges to the study of emotion regulation.

\section{First Things First-Definitional Challenges}

To distinguish the construct of emotion regulation from that of emotion, one must define emotion. Some have argued that emotions are inherently regulatory and that the two concepts cannot be distinguished (e.g., Stansbury \& Gunnar, 1994) or that our understanding of emotion is so limited it cannot be distinguished from emotion regulation (Kagan, 1994). To advance research in emotion regulation, the researcher must articulate a position in relation to these conceptual and definitional challenges and attempt to define the constructs.

\section{What Is Emotion?}

Unfortunately, there is no consensus on the nature of emotion. There are many theories of emotion, and each contemporary emotion theory offers a different definition. Consequently, there is no "gold standard" for methods of studying emotion. In our view, it is crucial for each emotion regulation researcher to articulate a conceptual approach and define the 
constructs invoked if work in this area is to be scientifically viable and rigorous. We approach the definitional challenge by adopting assumptions shared by the emotion theories most often cited in the literature on emotion regulation in early childhood (Barrett \& Campos, 1987; Frijda, 1986; Izard, 1977; Lazarus, 1991; Sroufe, 1996; Tomkins, 1962, 1991). Despite substantial differences among them, they share a neo-Darwinian influence, viewing emotions as biologically prepared capabilities that evolved and endured in humans because of their extraordinary value for survival. Emotions are a kind of radar and rapid response system, constructing and carrying meaning across the flow of experience. Emotions are the tools by which we appraise experience and prepare to act on situations.

We have extracted several assumptions about the nature of emotion from our reading of these various theories that influence our empirical efforts. We assume that emotions are biologically endowed processes that permit extremely quick appraisals of situations and equally rapid preparedness to act to sustain favorable conditions and deal with unfavorable conditions. The term appraisal, introduced by Arnold (1960), refers to the process of appreciating the specific significance of a situation (or perception or representation of a situation) for individual wellbeing (Barrett \& Campos, 1987; Frijda, 1986; Lazarus, 1991; Scherer, Schorr, \& Johnstone, 2001). Thus, emotions are partly defined as a means of evaluating experience. The process of appraising is linked to readiness to interact in certain ways with the environment (Arnold, 1960; Frijda, 1986). That is, appraisals are accompanied by tendencies to be ready to respond in a particular way. Whether appraisals cause emotions, whether emotions are appraisals, whether appraisals precede or co-occur with actionreadiness tendencies, whether specific discrete emotions are associated with specific discrete action tendencies - all these matters are unresolved in the literature. Therefore, we prefer the view, eloquently stated by Campos, Mumme, Kermoian, and Campos (1994), that appraisal and action readiness are the "warp and woof" that constitute the fabric of emotion. In thus describing these assumptions, there is a risk of treating emotions as things. But emotion is a process, a constant, vigilant process (Izard, 1977; Walden \& Smith, 1997), which periodically reaches a level of detection for the person (i.e., a feeling) or an observer (a friend, a parent, or even a developmental scientist).

These assumptions about the nature of emotion lead our work in the direction of trying to detect the ebb and flow of a child's emotions by observing the child in particular circumstances, which are known to afford particular appraisals and action tendencies, and measuring the child's emotional reaction in those circumstances. A focus on emotions as appraisal and action readiness directs methods away from reliance on the assessment of conscious experience and to observations of the relation between the person and the environment (Barrett \& Campos, 1987; Witherington, Campos, \& Hertenstein, 2001). Because emotions are so rapid and fluid, often involving micromomentary changes beyond the level of detection that current technology allows, they elude concrete or simple assessment. Observational methods only approximate such dynamic processes in children, but as we show, measures derived from observations can provide an adequate basis for inferring that emotion was activated and that regulation occurred.

\section{What Is Emotion Regulation?}

The construct of emotion regulation has been difficult to segregate from the construct of emotion (Campos et al., 1994; Kagan, 1994; Stansbury \& Gunnar, 1994). One reason, of course, is the historical lack of consensus on the definition of emotion. Moreover, because the process of appraisal and action readiness alters the experience and behavior of the self and others, emotions are inherently regulatory (Campos et al., 1994; Haviland-Jones \& Kahlbaugh, 2000; Izard \& Ackerman, 2000). If emotions are inherently regulatory, how then are emotion and emotion regulation distinct? We think it is possible to distinguish elements of appraising and readying to act, which has regulatory effects on action and social interaction, because emotions have different effects depending on how they are regulated. Thus, we suggest that one must attempt to infer specific emotions have been activated and independently infer regulatory processes.

A second, related complication is that emotions can be construed as having regulatory influences on domains of functioning that are intimately related to emotions. Emotions affect and are affected by physiological activity, including cardiovascular (Porges, Doussard-Roosevelt, \& Maiti, 1994), cortical (Fox, 1994), and neuroendocrine (Stansbury \& Gunnar, 1994) systems. These systems are not clearly distinct from emotions themselves. Garber and Dodge (1991) suggested that researchers distinguish intradomain regulatory processes (aspects of emotional responses influencing theoretically related components, such as physiological activity, attributions about the situation) from interdomain processes (aspects of 
emotional responses influencing theoretically distinct, separate systems, such as social interaction).

A third definitional complication is that the term emotion regulation is not only applied when emotion processes are thought to influence other processes; it is also applied to convey that emotions have the capacity to be regulated. Many studies have examined how individuals modify their emotional reactions, eliminating, minimizing, switching, amplifying, or redirecting them. Emotion regulation thus conceptualized provides a way of considering why one sad person seeks the solace of friends and another turns to mood-altering substances. A dynamic view of emotion regulation requires an appreciation that emotions are regulated even as they are regulating.

A fourth definitional issue concerns confusion about whether the term emotion regulation refers only to optimal functioning or includes maladaptive emotion regulation (Casey, 1996; Cicchetti, Ganiban, \& Barrett, 1991; Cole, Michel, et al., 1994; Garber \& Dodge, 1991; Keenan, 2000). To restrict the term for optimal functioning confounds emotion regulation with psychological health, overlooking the regulatory features of emotion in disturbed and at-risk individuals. That is, emotion regulation in a person with clinical problems, or at risk for them, is helping that person deal with present situations even as those very efforts may create risk for later or different problems (Cole, Michel, et al., 1994; Thompson \& Calkins, 1996). This confusion contributes to equating positive emotion with "goodness" and negative emotions with "badness."

A final issue that complicates our understanding of emotion regulation is related to the fact that emotions must be understood in context. Consider a preschool boy's apparent joy during an interaction with his mother. How do we determine whether this appearance of joy (smiling, laughing, lilting voice) is joy? We use context. Depending on other features of the interaction, we may conclude that the joy reflects the goal of maintaining interpersonal harmony or that it is rude and disrespectful, serving the goal of maintaining dominance in the interaction. Thus, not all joys are the same joy, although all may serve to maintain a desired goal (Barrett \& Campos, 1987; Kagan, 1994). But another set of contextual cues might lead us to say that the boy's expression of joy masks a different emotion, for example, that he is actually angry with his mother but is covering that over with apparent happiness. The joy is part of an effort to regulate the anger. Emotions are fluid and complex. The use of contextual variations and multiple cues is needed to converge on the correct inferences in any study.
In sum, research in emotion regulation has been plagued by a lack of clarity and definition. With this in mind, we describe the working definitions that help us navigate empirically through the difficult challenges of research in this area. They are the tools we have adopted, derived from the work of others, to guide research methods.

\section{Working Definitions of Emotion and Emotion Regulation}

Despite lack of consensus about what emotions are, ambiguities in the use of the term emotion regulation, and the technical challenges inherent in studying phenomena that are most surely micromomentary in nature, researchers must have working definitions to guide and advance research. Those definitions should lead to methods that provide strong inference (a) that an emotional state was activated and (b) that regulatory processes occurred independently. In following our own advice, we summarize the working definitions we use. As we have said, they are derived from the works described previously. Emotions are appraisal-action readiness stances, a fluid and complex progression of orienting toward the ongoing stream of experience. Emotions are moving targets that are usually unseen (and unfelt). Emotions must be inferred from evidence of the individual's relation to surrounding events. We use the word stance to imply, as others have, that emotions involve being poised, oriented, ready, or inclined toward a course of action. The term stance connotes that the individual is evaluating a situation (appraising) and inclining toward a particular class of actions (action readiness).

Emotion regulation refers to changes associated with activated emotions. These include changes in the emotion itself (e.g., changes in intensity, duration; Thompson, 1994) or in other psychological processes (e.g., memory, social interaction). Emotion regulation is not defined by which emotions are activated but by systematic changes associated with activated emotions. Thus, evidence that one person is angrier than another does not by itself show that the first person is regulating anger differently from the second.

The term emotion regulation can denote two types of regulatory phenomena: emotion as regulating and emotion as regulated. In each case, the regulatory aspects must be conceptualized independently of which emotion is activated initially. Emotion as regulating refers to changes that appear to result from the activated emotion. Again, the distinction between intradomain and interdomain changes bears repeating (Garber \& Dodge, 1991). An independence of emotion and regulation, applied to intradomain changes, must be carefully considered and justified theoretically. 
Intradomain changes (e.g., relations between fear, as judged by facial expression and behavior, on an emotion-related system such as cardiovascular activity) may reflect the systemic nature of emotion rather than an independent emotion regulating a separate system (Stansbury \& Gunnar, 1994).

Emotion as regulating also refers to interdomain changes (e.g., a child's sadness altering a caregiver's discipline strategy). In the latter case, the researcher momentarily segregates emotion process and social process, much as a snapshot captures a moment, while appreciating that the two are inextricably related. Systematic evidence that one's own, or another's, activity changes the valence, intensity, or duration of an activated emotion constitutes evidence of emotion as regulating.

Emotion as regulated refers to changes in the activated emotion. These include changes in emotion valence, intensity, or time course (Thompson, 1990, 1994) and may occur within the individual (e.g., reducing stress through self-soothing) or between individuals (e.g., a child makes an unhappy parent smile). Interdomain changes are closely related to the regulation of emotion. For example, a day care worker changes his or her discipline strategy in response to a youngster's sadness and the youngster's sadness is modified by the new caregiver behavior and then, it is hoped, both feel better than they had. Emotion as regulated is not limited to such positive scenarios, however, and can include examples of strategies that may be judged by other criteria as maladaptive (e.g., Cole, Michel, et al., 1994).

Until advances in research methods afford new and improved definitions, emotion regulation researchers must provide working definitions of their constructs to increase clarity. Furthermore, there is a need for operational strategies that provide a strong empirical basis for inferring emotion regulation. Methods that demonstrate change promise to contribute to the understanding of emotion regulation more than methods that focus solely on emotion valence. If change cannot be captured as an index of regulatory processes, creative uses of contrasting conditions and multiple, converging measures offer promise for increasing the level of inferential interpretation. We next illustrate these points by describing studies that have provided compelling evidence with which to infer emotion regulation in early childhood.

\section{Developmental Evidence for Emotion Regulation}

At present, research in emotion regulation faces technical limits in distinguishing emotion regulation from emotion itself. It is difficult to distinguish the initial intensity of an emotional reaction from regulation of that emotion (Kagan, 1994). At the physical level, emotional reactions emerge from neural activity that occurs in milliseconds (see Davidson, Jackson, \& Kalin, 2000). Traditional emotion measures (e.g., facial expression, subjective report, physiological markers) are as likely to reflect regulatory influences as they are emotional reactions per se. Although technical advances may some day permit the capturing of an emotion in progress, at present we need consensus on how best to use existing methods to provide the strongest inference that emotion regulation is being studied (Fox, 1994).

In this section we provide examples of studies from the child development literature that provide evidence for the construct of emotion regulation. Our criteria for selecting a study were that it (a) attempted to assess emotion independently of purported regulatory phenomena and (b) assessed either outcomes that were related to activation of an emotion (emotion as regulating) or factors that caused changes in emotion (emotion as regulated). Our goal was not an exhaustive review of the broad and amorphous emotion regulation literature, but an illustration that a substantive basis for inferring emotion regulation can be achieved. For conciseness, we focus on three areas of research, each of which addresses the complexities of emotion regulation as a scientific construct: infant temperament, mother-child face-to-face interaction, and early childhood emotional self-regulation. They suggest a developmental sequence in which infants first have a basic self-regulatory capacity for managing emotion of varying and limited effectiveness, then engage in mutually regulatory interactions with their mothers, and finally develop an array of additional self-regulatory strategies over the toddler and preschool years.

\section{Evidence From the Study of Infant Temperament}

The concept of temperament refers to innate individual differences in infants. The specific nature of those differences has been debated, but researchers have come to agree that temperament involves, in part, individual differences in emotion (Goldsmith et al., 1987). That is, individual differences in infant temperament reflect biologically based biases toward the experience and expression of certain emotions. Two approaches to the study of infant temperament have yielded evidence that emotions are regulated.

The first approach defines temperament as individual differences in (a) reactivity, that is, the speed and intensity of the initial activation of an 
emotion, and (b) self-regulation, that is, the capacity to modify the intensity and duration of that initial emotion by engaging in behavioral strategies such as gaze aversion, self-sucking, or proximity seeking to a caregiver (Rothbart \& Bates, 1998; Rothbart \& Derryberry, 1981). Empirical evidence derived from this model has yielded two types of findings that contribute to the inferential basis for emotion regulation: (a) purported self-regulatory behaviors were more likely to occur during experimental emotionactivating conditions in contrast to conditions that were not designed to activate a specific emotion and (b) purported strategies were likely to occur when infants appeared distressed (facial grimaces, distress vocalizations) and not during periods of neutral or positive infant emotion expression (e.g., Buss \& Goldsmith, 1998; Calkins \& Johnson, 1998; Rothbart, Ziaie, \& O'Boyle, 1992).

A few temperament studies further contributed to the evidence of regulation by testing whether enactment of putative regulatory behaviors, after a specific emotion was activated, altered infant emotion expression, behavior, or physiology. Buss and Goldsmith (1998) examined regulatory strategies in relation to fearful and angry distress expressions of 6-, 12-, and 18-month-olds during emotion-activating procedures. Emotions were activated using a barrier to an attractive toy and arm restraint (anger activation) and during exposure to two novel toys, a remote-controlled spider and an unpredictable mechanical dog (fear activation). Infants' emotions and regulatory behaviors were coded independently in 5- to 10-s intervals. Contingency analyses indicated that some, but not all, purported regulatory strategies were followed temporally by a reduction in anger intensity but rarely in fear intensity. Their findings provide a basis for inferring that infants regulate emotions to a limited degree.

Similarly, Stifter and Braungart (1995) observed 5- and 10-month-old infants during conditions designed to activate anger: arm restraint and toy removal. During each procedure, infant negative emotion was scored in 10-s intervals, and regulatory behaviors (e.g., gaze aversion) were coded continuously. Consecutive intervals in which reactivity increased, decreased, or remained constant provided an operational definition of change in negative emotion. Results indicated that two purported strategies (self-soothing and orienting) were more likely to occur in intervals of decreasing negativity than in intervals of stable or increasing negativity. In sum, these two studies provide strong evidence that emotions are regulated by capitalizing on timebased, microanalytic techniques for linking change in activated emotions with putative regulatory strategies. Strengths of their methods were: (a) using experimental procedures to activate target emotions, (b) assessing infant emotion independently of purported regulatory behaviors, (c) assessing infant emotion and regulatory behavior over time, and (d) establishing predicted temporal relations between regulatory efforts and changes in activated emotions.

Arguably, observations of change in emotion as a function of regulatory behavior provide the clearest evidence on which to base inferences that emotions are regulated (cf. Harman, Rothbart, \& Posner, 1997). Other research methods have also been used. Stifter, Spinrad, and Braungart-Rieker (1999) employed multiple measures to infer regulatory processes by adding physiological assessment of cardiac activity (i.e., vagal tone, an index of parasympathetic regulation of heart rate) to independently derived ratings of emotion and behavioral strategies. Building on their previous work using temporal analyses (Stifter \& Braungart, 1995), they demonstrated predicted differences in patterns of convergence among measures to add to the evidence that children of different temperaments regulate emotions differently.

A second approach to temperament research involves studies of behavioral inhibition (Kagan, 1999; Kagan, Snidman, \& Arcus, 1993). The trait is defined by the degree to which an infant or young child is shy and fearful and withdraws in novel, uncertain situations. In the standard paradigm, experimental fear-activating procedures (novel conditions) are employed and measures of emotion (fear intensity), behavior (e.g., withdrawal, which is hypothesized to accompany fear), and physiological activity are collected. Predicted relations among the measures are shown for toddlers who were judged independently to be significantly above average in fearfulness and wariness. Fox (1994) extended the conceptualization of behavioral inhibition to include emotion regulation. He proposed that individual differences in inhibition are explained by two factors: (a) a propensity to react fearfully to novelty and (b) difficulty in effectively modulating fear. Thus, it is not just the proclivity to react with fear but difficulty in regulating fear that leads to highly inhibited behavior.

Evidence for this argument has relied on demonstration of hypothesized relations among multiple measures. Because patients with certain areas of frontal lobe damage have self-regulatory deficits, it has been deduced that patterns of frontal area activation during fear-activating conditions reflect difficulties in emotion regulation in temperamentally inhibited children (Davidson, 1985; Fox, 1994; 
Kinsbourne, 1982). Briefly, predominant activation of the left frontal cortex (left frontal asymmetry) should be associated with approach behaviors (positive emotion expression, sociability), whereas hypoactivation of the area should be associated with deficits in approach tendencies (absence of positive emotion). Predominant activation of the right frontal cortex (right frontal asymmetry) should be associated with withdrawal tendencies (negative emotion expression, active withdrawal) and hypoactivation with deficits in withdrawal (inability to inhibit approach). Thus, if temperamentally inhibited children have emotion regulatory difficulty, they should manifest hypoactivation of the left frontal area or activation of the right frontal area.

Evidence for emotion regulation in this approach to temperament has relied on observations of children in context but has not employed temporal analyses of change. Rather, it has relied on demonstrating predicted patterns among multiple measures as convergent evidence of emotion regulation. Behaviorally inhibited toddlers differ in predicted ways from noninhibited toddlers: in their emotional reactions to novel stimuli, in their use of purported emotion regulatory strategies, and in concomitant patterns of EEG frontal activity, as shown in a series of studies from different research programs (e.g., Fox, 1994; Mangelsdorf, Shapiro, \& Marzolf, 1995). For example, 6-, 12-, and 18-month-olds classified as wary or fearful by their mothers engaged in different regulatory behaviors from their bolder peers; they averted gaze and avoided a stranger more than children described as bold (Mangelsdorf et al., 1995). Evidence that these patterns are associated with cortical activity, known to be associated with regulatory processes, strengthens the inference that emotions are being regulated. Four-month-olds who were judged to be irritable showed the predicted convergence of right frontal asymmetry when they were 9 months old and more inhibited behavior (an aggregate of being slow to touch and vocalize and of seeking proximity to mother) in the presence of novel stimuli when they were 14 months old in contrast to infants who were judged to be exuberant (Calkins, Fox, \& Marshall, 1996). A similar pattern emerges in studies of older children (Fox et al., 1995; Schmidt, Fox, Schulkin, \& Gold, 1999).

The temperament studies described thus far focused on reactivity in the fear system, but a similar approach to emotion regulation has been taken in studies of temperamental anger. For example, Calkins, Dedmon, Gill, Lomax, and Johnson (2002) classified 6-month-old infants as easily or less easily frustrated on the basis of parent report and labora- tory assessment and then compared them on a set of coherent measures of regulatory capacity. The latter measures included independent assessments of regulation of anger, attention, and activity, as well as cardiac activity (respiratory sinus arrhythmia [RSA]). Easily frustrated infants exhibited the predicted cluster of characteristics: They engaged in less distraction and more physical acting out, they were less attentive, they were more active, and they had lower RSA suppression than less easily frustrated infants. In a study of 2-year-olds, Calkins and Dedmon (2000) showed that higher risk (as defined by externalizing symptoms) toddlers were more emotionally negative than lower risk toddlers during laboratory tasks. Convergent evidence that frustration was poorly regulated by high-risk toddlers was inferred on the basis that they were more behaviorally disruptive (e.g., noncompliant, distractible, inattentive), and therefore poorly regulated behaviorally, and showed lower RSA suppression than the low-risk toddlers.

\section{Evidence From the Study of Mother-Child Interaction}

Broadly speaking, psychologists have focused on emotion regulation as a process that occurs within the person. The interpersonal nature of emotion regulation has been established in research on mother-child interaction. In this framework, the emphasis moves from a focus on infant self-regulation to the complex ways in which emotions are both regulated and regulating in social interaction. Work in this area conceptualizes one partner's emotions as systematically influencing the other partner's emotions and behavior. In recursive discourse, each partner's emotions regulate the other and are regulated by the other. The quality of such exchanges is hypothesized to be a crucial predicate of a variety of developmental outcomes, including the child's growing ability to self-regulate emotion. Thus, emotion as regulating social interaction is intricately tied to the development of the capacity to regulate one's own emotions.

Early work observed moment-to-moment interactions between infants and mothers, predicting spontaneous and mutual contingency between partners and reciprocal regulation of dyadic emotional communication (e.g., Cohn \& Tronick, 1988; Field \& Fogel, 1982; Fogel, 1993; Gianino \& Tronick, 1988; Stern, 1985; Trevarthen, 1984; Tronick, 1989). Observations of maternal and infant expressive behavior were recorded and coded continuously and independently, then were analyzed to examine the timing and sequencing of changes in each partner of 
the dyad. For example, Field (1994) demonstrated synchrony between mother and infant expressive behavior (facial and vocal activity) and their physiological responses. The findings were interpreted as evidence that typical mothers and infants are sensitive to each other's emotional signals, reciprocate by matching emotion or modifying behavior to amplify or modulate the other's emotion, and sustain an ebb and flow of emotional interaction that maintains the relationship in a sensitive, optimal way. Mothers regulate infant emotional states by reading infant emotional signals, providing appropriate stimulation, modulating levels of infant arousal, and reciprocating and reinforcing infant reactions. Infants regulate their mothers' emotions through their receptivity to mothers' initiations and stimulation, approaching and withdrawing from stimulation, and responding contingently to maternal emotion.

The quality of these emotion exchanges is conceptualized as an important precursor of the developing child's ability to regulate his or her own emotions. For example, sophisticated analyses of mother-infant synchrony, using statistical procedures that control for the naturally occurring autocorrelations in the individual's own stream of emotion, indicate that the quality of dyadic emotion regulation in infancy predicts toddler self-control (Feldman, Greenbaum, \& Yirmiya, 1999). Moreover, interpersonal or mutual regulation of emotion is not a phenomenon of infancy only. It has also been observed in studies of parent interaction with toddlers and with preschoolers (e.g., Cole, Teti, \& ZahnWaxler, 2003; Denham, 1993; Dumas, LaFreniere, \& Serketich, 1995). These studies use laboratory procedures to tax the dyad by simulating ordinary challenges that young children face in their lives. In most cases, the procedures attempt to stimulate a child's desire for an activity or object and then block access to it. Typical procedures of this sort, designed to activate frustration and anger, include requiring a young child to clean up toys, to wait for mother to finish work to get a desirable object, to resist touching prohibited toys, or to persist at a difficult task. Such studies also include tasks that support positive emotional exchanges (e.g., snacks, free play, receiving the toy).

The procedures elicit social interactions, which are then coded for emotional cues. Mother and child emotion, as inferred on the basis of facial and vocal cues, are coded independently but are time synchronized to permit demonstration of contingent relations between each partner's reactions (Cole et al., 2003; Denham, 1993). For instance, using con- tinuous recording of the onset and offset of mother and child emotion displays, Denham (1993) examined mother-toddler "emotional dialogues" across a situation that afforded positive emotions (eating lunch) and one that afforded negative emotions (being measured by a doctor). Analyses revealed contingencies in mother-child emotion displays, with results suggesting that mothers and children responded emotionally to each other in predictable, systematic, and temporally contingent ways.

Research on the dynamics of early parent-child emotional interactions provides evidence for emotion regulation by demonstrating reliable, contingent changes in mother and child emotionally expressive behavior. Those changes are contingent on the partner's emotional communication and are not a function of the cycling of individual expressivity (e.g., Cohn \& Tronick, 1988). These changes involve coconstructed coordination, including matching of positive emotions and repairing of negative or mismatched emotions (Field, Healy, Goldstein, \& Guthertz, 1990; Stern, 1977; Trevarthen, 1984; Tronick \& Cohn, 1989). Moreover, changes in emotion expression and behavior are associated with contingent changes in physiological activity in each partner (Field, 1994). The time-based methods employed to capture these processes are well suited to inferring that one partner's emotions are regulated and regulatory. The inference is further strengthened by the inclusion of multiple and synchronized measurement strategies (e.g., time-linked facial and cardiovascular recordings).

Another approach to examining emotion regulation capitalizes on the effects of perturbations of the expected course of social interaction. The still-face paradigm (Tronick, Als, Adamson, Wise, \& Brazelton, 1978) reliably demonstrates systematic changes in children's emotion as a function of changes in maternal affect, thereby offering another avenue for inferring emotion regulation. In the standard threeperiod procedure, mother and infant first engage in spontaneous interaction. Next, the mother is instructed to be emotionally unresponsive for a short period, keeping her face still and neutral. Finally, the mother is asked to resume her spontaneity.

Findings generated with this method show that when the mother is still, most infants (a) change emotionally, specifically decrease smiling and increase signals of distress; (b) behave as if they are trying to re-engage the mother by vocalizing and gesturing at her; and (c) avert gaze from the mother as efforts to re-engage her fail. During the final relief phase of the procedure, infants resume looking at the 
mother with increased positive emotion expressions. These emotional and behavioral changes across episodes are also accompanied by changes in autonomic activity (Weinberg \& Tronick, 1996). Moreover, research using the still-face procedure has demonstrated changes, not only in infants' emotion, behavior, and physiology but also in the coordination of dyadic interaction. Weinberg, Tronick, Cohn, and Olson (1999) used second-by-second coding to demonstrate that the disruption of the interaction when maternal emotion is constrained interferes with the mutual regulation of the dyad. Examining the reunion phase, they showed a carryover of negative emotion from the still-face phase as well as changes in mother-infant coordination compared with previous phases.

Changes in the timing and sequencing of dyadic communication suggest that emotion regulates social interaction. In addition, manipulations of specific elements of the still-face procedure provide contrasts that further illuminate the presence of emotion regulation. That is, contrasting conditions afford ways to demonstrate that a mother's emotions are regulating an infant's emotions or that an infant is attempting to engage in self-regulatory behavior (Stack \& Muir, 1990, 1992). As in the temperament area, researchers who have established evidence of change often add to the body of evidence by measuring multiple domains to provide convergent evidence of regulatory phenomena (Weinberg \& Tronick, 1996).

Across studies using the still-face procedure, it has been shown that infants actively engage in behaviors that should regulate the social interaction (vocalizing, gesturing, and communicating distress) and initiate self-regulatory strategies when other regulatory strategies fail (e.g., avert gaze, self-sooth). Furthermore, several studies identified specific associations between infant expressive behavior and purported strategies, thereby strengthening the inference that observed changes were reflective of a regulatory process. For example, Braungart-Rieker, Garwood, Powers, and Notaro (1998) found correlations between ratings of 4-month-old infants' positive and negative expressions and purported regulatory behaviors. Compared with infants who exhibited more positive emotion during the still-face procedure, infants who exhibited more negative emotion engaged in less self-comforting and less orienting toward an object or the parent. Weinberg and Tronick (1994) also reported associations between certain emotional states and behaviors that are hypothesized to be regulatory strategies. Contingency analyses revealed that infant facial anger during the still-face procedure co-occurred with pick-me-up gestures, attempts to escape or distance from the situation, distress vocalizing, and signs of autonomic distress (e.g., spitting up). Anger did not co-occur, however, with other behaviors purported to be self-regulatory strategies, such as self-distraction; these occurred in synchrony with neutral or positive expressions.

Evidence of emotion regulation based on the use of contrasting conditions is not limited to face-to-face interactions in laboratory conditions. Lamb and Malkin (1986) conducted a longitudinal design of infants from 1 to 7 months old in their homes. They focused on distress relief when infants cried, contrasting conditions of the mother or a female research assistant responding to the infant. They also varied the delay between infant cry and adult relief (immediate or after a 60-s delay). Comparisons across conditions revealed that the arrival of the adult was associated with anticipatory calming (i.e., quieting before being picked up) and that the delay was associated with infant protest, especially when the mother arrived but did not respond. Again, the method used to infer social expectation suggests early infant emotion regulation (initiation of behaviors that regulate mother, i.e., protest) and inchoate self-regulation (calming in anticipation) with the added value of being done in nonlaboratory conditions.

\section{Evidence From the Study of Emotional Self-Regulation}

The third area of study that provides evidence of emotion regulation is the study of the early emergence of self-initiated attempts to modulate negative emotion. Advances in cognitive, motor, and language development occur during the second through fifth years of life, which permit children to apply a broader range of abilities to the regulation of their own emotions than they could in infancy (Kopp, 1989; Kopp \& Neufeld, 2003; Thompson, 1990, 1994). For example, during the second through fourth years, there is evidence of a decrease in the use of self-soothing and the emergence of new and more complex use of objects and interactions to regulate emotional state (Diener \& Mangelsdorf, 1999).

Studies that provide a substantive basis for inferring that young children regulate emotions also rely on observations of children under challenging conditions that afford negative emotions. For example, separation from a parent arguably activates the fear system and obstacles to getting a desired object activate emotions from the anger family. During these procedures, children's emotionally 
expressive behavior is coded, continuously or in brief epochs, to provide evidence that target emotions were activated. A variety of strategies have been employed to then argue that young children in these emotional situations are regulating their emotional states. Studies based on such methods have shown that (a) young children engage in a variety of putative self-regulatory attempts when faced with challenging situations and (b) enactment of those behaviors is associated with negative emotion.

For example, Grolnick et al. (1996) examined regulatory strategies in toddlers who experienced a separation from mother and a delay in receiving a desirable object. Several social condition manipulations - observing the child's handling of distress when alone, with the experimenter, with the mother when she was passive, and with the mother when she was active-provided more context for inferring emotional self-regulation attempts. Toddler emotionally expressive behavior was coded every $5 \mathrm{~s}$ to create variables that indexed level of intensity and temporal changes in emotional expression for each condition and situation. A principal components analysis revealed that these intensive and temporal variables were highly related and they were aggregated into a single composite score. Independently, self-regulation strategies were coded for the same intervals; these included self-distraction, self-soothing, and bidding for parental attention. Under these emotion-activating conditions, the more a toddler engaged with his or her surroundings, the less negative emotion was seen, but the more a toddler focused on the person or object withheld, the more negative emotion was observed. Toddler self-distraction occurred more frequently if an adult was present and behaving freely than when the child was alone or the adult was passive. This pattern of results was interpreted as evidence that a toddler can engage in a presumably effective selfregulation strategy when social support is present even if that support is not directed at helping the child cope.

Thus, the study hinted that self-distraction was an effective strategy for toddler regulation of fear and frustration. Although this interpretation is consistent with a hypothesis that reallocation of attention can regulate distress, Grolnick et al. (1996) cautioned that the method did not demonstrate that distraction actually changed toddlers' emotional states. Purported regulatory efforts may coincide with different emotion expressions without necessarily modifying them. For example, toddlers who actively engaged in their surroundings may have shown less negative emotion because they were less distressed. That is, the co-occurrence or correlation between two sets of independent codes - emotion and regulatory efforts - is insufficient to conclude that the efforts regulated the emotion.

Diener and Mangelsdorf (1999) addressed the issue in a different manner. Toddlers' putative regulatory attempts were observed during fear- and anger-activating laboratory procedures. Specifically, 18- and 24-month-olds and their mothers were observed during six emotion-activating tasks. They included a manipulation of maternal involvement to examine toddlers' self-initiated regulatory efforts by instructing mothers to refrain from initiating interaction with the child for the first half of each task. Toddlers' efforts and emotional expressions were coded independently in 15-s intervals. Contingency analyses were used to link regulatory efforts to changes in emotion. That is, they examined whether changes in emotional expression temporally followed regulatory attempts. Certain self-initiated behaviors were followed by reduced negative emotion. The effectiveness of self-regulatory efforts varied as a function of which emotion was activated. Furthermore, some purported regulatory behaviors (e.g., distraction) were not associated with reductions in anger or fear.

A similar approach was adopted in a study of anger regulation in preschool boys (Gilliom, Shaw, Beck, Schonberg, \& Lukon, 2002). Children were observed during a frustration-activating task (i.e., having to wait to get a cookie). Purported regulatory efforts and peak intensity of anger expressions were coded independently in 10-s epochs. Temporal contingency analyses were then used to assess if and how anger changed following a regulatory effort. Some regulatory efforts (e.g., focusing on the desired object) were associated with increased anger expression. However, other regulatory efforts were presumed to improve behavioral self-control in as much as certain strategies, and the frequency and diversity of regulatory strategy use, were associated with self-control when the boys were 6 years old. Thus, the methods in these studies provide useful evidence that young children can engage in emotional self-regulation and that the manner of such efforts is predictive of later outcomes. The evidence is bolstered by methods that contrast task elements (e.g., constraining maternal behavior), inclusion of multiple factors conceptually related to the prediction of emotional self-regulation in children (e.g., temperament, quality of parent-child interaction), and longitudinal evidence of the predictive validity of earlier self-regulatory efforts.

Manipulations of social context, such as constraining an adult's efforts to help a child, have been 
used to infer emotional self-regulation in preschoolage children. Saarni's (1984) disappointment procedure was adapted to examine expressive control in preschool-age children (Cole, 1986). Various adaptations were used to strengthen inferences that children who smiled when receiving a disappointing prize were actually regulating the expression of disappointment. Each child ranked a set of prizes before the procedure to establish their actual preferences. This also created an expectation that the most preferred prize would be received. After doing some work, each child was given the last choice prize (usually a broken toy), a procedure that further strengthened the inference that each preschooler was disappointed. Evidence suggested that preschoolers tried to hide their disappointment (smiling despite receiving a broken or last choice prize), but the procedures did not permit sufficient basis on which to conclude that the smiling child was actually disappointed. Thus, a follow-up study (Cole, 1986) used a between-subjects variation of social conditions. The experimenter left the child with the disappointing prize in one condition but stayed with the child in the other social condition. Evidence that preschoolers displayed more positive and less negative emotion with the experimenter but more negative and less positive emotion when alone built a stronger case that preschoolers were regulating negative emotions. This finding of spontaneous expressive control in young children has been replicated (Cole, Jenkins, \& Shott, 1989; Cole, Zahn-Waxler, \& Smith, 1994; Davis, 1995; Garner \& Power, 1996; Josephs, 1994).

Further research with this procedure used a within-subject manipulation of social conditions and a postprocedure interview to provide more support for inferring that children felt negative emotions but regulated their expressions of them (Cole, Zahn Waxler, et al., 1994). In this study, the experimenter gave the preschooler his or her last choice prize, remained with the child for $1 \mathrm{~min}$, making eye contact but appearing neutral, and then left the child alone for $1 \mathrm{~min}$. Negative emotions occurred more when preschoolers were alone and positive emotions occurred more frequently when the assistant was present. The postprocedure interview, conducted with a different assistant, provided additional evidence that preschoolers were actually disappointed. All reported feeling negatively (mad, bad, angry, and sad) about getting the last choice prize and all traded that prize for previously preferred prizes when given the option. In sum, the combination of contrasting social conditions and multiple, converging measures provided a substantive basis for studying emotion regulation in toddlers and preschoolers.

\section{Methodological Directions for Research on Emotion Regulation}

Future research in emotion regulation, whether it attempts to demonstrate that emotions are regulatory or regulated, bears a greater burden for demonstrating regulatory processes than studies of the last two decades have borne. Challenging as that burden is, and given the technical limits on capturing an emergent, dynamic process such as emotion, the studies reviewed constitute an impressive body of literature that provides strong inferential evidence for the construct of emotion regulation. Four useful methods have been used across different subsets of these studies. The most compelling evidence for emotion regulation has emerged from studies, or series of studies, that have used combinations of these tools. They do not necessarily exhaust the creative possibilities but they are exemplars that can guide and foster new methods in emotion regulation research. These methods are:

1. independent assessment of activated emotion and purported regulatory strategies,

2. analysis of temporal relations between emotion and regulatory phenomena,

3. comparison of emotion and regulatory phenomena in contrasting conditions, and

4. use of multiple, converging measures to demonstrated predicted organization of emotion regulatory responses.

\section{Independent Measurement of Activated Emotion and Purported Regulatory Strategies}

Most studies in the early child development literature rely on observational methods in large part because very young children have considerable difficulty reflecting on and reporting their emotional experiences. Acknowledging that emotions are micromomentary, dynamic processes, aspects of which are difficult to capture scientifically, it is nonetheless important to emotion regulation research that investigators avoid confounding emotional valence with emotion regulation. Interpreting the level at which a child manifests negative emotion with poor regulation compromises the studying of both the regulatory and regulated aspects of emotion (Cole, Zahn Waxler, et al., 1994; Maughan \& Cicchetti, 2002; Thompson, 1994).

In addition, many of the studies that provide strong inference make their observations under controlled or quasinaturalistic conditions that are designed to afford, and therefore heighten, the probability of activating particular emotions. This 
increases the level of inference that can be drawn and attempts to control, to a degree, contextual factors that are integral to inferences about emotion. As emotion theories predict, and research has shown, novel stimuli and separation from mother afford emotions related to fear; blocked goals, violated expectancies, and injustices afford emotions related to anger; and positive adult attention and desirable objects afford emotions related to happiness. The laboratory methods used in the studies reviewed therefore provide a means of inferring that certain emotions were likely to be activated.

It appears that laboratory studies have also been effective at assessing emotion and regulatory features independently. Although there have been clever uses of home observations to infer regulatory processes (Lamb \& Malkin, 1986), most of the strong evidence for emotion regulation has occurred under laboratory control. It is not that naturalistic studies should be avoided; to the contrary, it is just that thus far controlled studies have been able to distinguish emotion activation from regulatory effects or efforts. They provide the evidence that other researchers can rely on when such controlled conditions are not possible or even desirable to study a particular question. The distinction is crucial to be able to argue that emotions regulate behavior (e.g., a preschooler's anger can organize problem solving; Wiggins, Cohen, Gitter, Zalewski, \& Cole, 2003) or that emotions can be regulated (a toddler's averting gaze minimizes fear; Buss \& Goldsmith, 1998; Diener \& Mangelsdorf, 1999). Most studies using such procedures infer emotions were activated on the basis of a set of expressive behaviors (facial, vocal, and sometimes gestural). The evidence is even more compelling when additional measures, such as physiological assessments (e.g., heart rate, vagal tone) or child selfreport, offer convergent evidence. No single source of data provides unequivocal evidence that an emotion was activated for each or all children, because of the micromomentary nature of appraisal and action readiness, and the highly dynamic, contextually bound nature of emotion processes. In combination, however, multiple measures can be used to infer that an emotion was activated.

\section{Temporal Relations Between Emotions and Regulatory Phenomena}

One of the most compelling ways of demonstrating change is the examination of temporal relations between variables. This has long been a strategy in developmental psychology, in which longitudinal data increase the ability to study and infer change.
Just as development is constantly in motion, emotions, too, are ongoing and constantly changing dynamic processes. Time-synchronized assessment and temporal analyses are tools that can be used to infer emotion regulation. In studies of temperament and of the early development of emotional self-regulation, there have been successful efforts to demonstrate that young children deploy behavioral strategies that regulate their emotional states. For example, a reduction in the initial intensity of a fearful reaction when a child averts gaze from a novel stimulus that affords fear constitutes a form of evidence that the gaze shifting altered the intensity or the presence of fear.

In parent-child interaction research, temporal analyses have been used to demonstrate the mutual regulation involved in social interactions - emotions regulate and are regulated in these dyadic exchanges. These studies synchronize independent assessments of emotion and regulatory phenomena in time and employ a variety of methods for analyzing relations among variables. Some studies have used sophisticated strategies such as time-series analyses and sequential analyses, controlling for autocorrelations within individuals to demonstrate coregulatory processes. Others simply use contingency analyses or create variables that incorporate the contingency and subject those to statistical tests. Moreover, a variety of statistical approaches can be employed when needed to capture emotion regulation as a process, including a variety of sequential and time-series techniques (e.g., Bakeman, 1997; Giardino, Lehrer, \& Feldman, 2000; Sackett, 1987).

Empirical studies are needed to examine whether emotions can change in the absence of regulation or whether, for example, the dynamics of emotion (e.g., latency to return to a baseline state) reflect allostasis, or stability, in response to internal and external changes (see McEwen \& Seeman, 1999, for an example from stress research). Investigators who study temporal relations among measures of inferred emotion and measures of regulatory phenomena must temper their interpretations. They can nonetheless yield substantive evidence of emotion regulation by demonstrating change. Regulation is fundamentally change; demonstration of change over time is one tool that can be used to advance research on emotion regulation.

\section{Contrasting Conditions}

A third tool used to examine emotion regulation is the use of contrasting conditions. Two types of contrasting conditions are used in the studies reviewed: 
contrasts of social context and contrasts of situational context. In contrasts of social context, a particular pattern of emotional regulation is predicted in a context that affords a certain class of emotional reaction (e.g., toy removal affords frustration or anger, separation from mother affords fear or anxiety). In most of the studies we have cited, the contrasting conditions are two or more manipulations of the social circumstances. Variations include manipulating the presence an adult (mother or research assistant present and absent), the nature of the prior relationship between the attending person and the child (parent, stranger), and the behavior of the adult (adult behavior constrained, unconstrained).

For example, observing a child alone may afford the opportunity to observe and evaluate self-regulatory efforts that might not occur when a parent is present, the logic being that the child relies on the parent rather than manages independently. In other cases, observing the child alone affords assessing emotions that are masked in the presence of another (e.g., an experimenter), as in the case of children masking disappointment. Contrasting conditions help the researcher around the problem of inferring emotion when there is barely a detectable sign of it. These are but a few examples that illustrate how contrasts of social conditions can further our efforts to disentangle evidence of emotions being activated and evidence of regulatory processes.

Another approach to the use of contrasting conditions involves the comparison of situations that afford different emotional reactions, that is, situational context. In the literature we have reviewed, several studies contrasted anger- and fear-activating conditions. Others contrasted nonchallenging (e.g., snack time, free play) with emotionally challenging conditions or contrasted variations in elements of a challenging situation. In most of these studies, a range of emotions was measured to verify that the particular emotions afforded by the challenging context were activated, and in some cases the emotions exhibited in the challenging context were compared with contexts that are less likely to afford those emotions (e.g., a blocked goal task in contrast with a novel, uncontrolled object exposure or a free play). These various approaches to contrasting situational context provide valuable ways to infer emotion and to demonstrate that different emotions may be regulated in different ways.

\section{Multiple, Converging Measures}

A final strategy involves using a set of converging measures to demonstrate predicted relations among elements of the larger construct of emotion regulation. There has been a tradition in emotion research to use the convergence of self-report, expressive behavior, and physiological change as definitive evidence of an emotion. The problem of course is that requiring such convergence limits research to only one aspect of emotion processes. For example, an emotion can be activated without its being a conscious phenomenon available to self-report. In several studies of emotion regulation, independent measures of emotion expression, behaviors that are purported to be self-regulatory, and physiological indexes associated with regulation (e.g., vagal tone, frontal asymmetry) were assessed. This multiplemeasure strategy can also include using self-report of child or mother, observations of emotion and behavior under contrasting conditions, and manipulations of conditions to heighten inference. Each of the three topical areas we described include studies that used this approach, but it has been employed most convincingly in programs that also used temporal analyses. The risk in studies that rely only on converging measurement is that they alone do not demonstrate change. That inference requires more strategies, such as temporal analyses or contrasting conditions. Findings that children who are characteristically fearful or inhibited also (a) react to novel stimuli with intense fearfulness, (b) do not avert gaze from the threatening situation, and (c) show low levels of vagal tone or frontal asymmetry, offer converging evidence that emotion organizes vigilance for dangerous stimuli but do not demonstrate that uninhibited children are actually regulating their fear by averting gaze. Nonetheless, research programs in the development of emotion regulation that fail to use multiple, converging measurement omit a compelling strategy for heightening inference.

\section{Summary and Conclusions}

In this article we identify methodological challenges in the study of children's emotion regulation and summarize a series of studies that appeared to address these challenges well, and on the basis of those studies, we suggest guidelines for future empirical work. Our purpose was to stimulate discussion and debate, hoping that the process would provide a context for improved research in the development of emotion regulation. We summarize previous work on conceptualizing emotion and emotion regulation, noting several challenges in each of these domains, and provide exemplars from the study of emotion regulation in early childhood that provide sub- 
stantial evidence for inferring emotion regulatory processes. In addition to studies of the development of emotional experience, expression, and understanding, child development research can be enriched by studies of how children's emotions organize their thinking, learning, action, and relationships, and how their thinking, learning, action, and relationships help them acquire the ability to regulate their own emotions.

There is as yet no gold standard by which to evaluate the scientific rigor of studies of emotion regulation. The field has struggled in its effort to move forward because of poorly designed studies and overinterpretation of findings. Because the assessment of emotion, and of emotion regulation, is necessarily inferential in nature, it is important to conceptualize carefully and measure rigorously these phenomena, building the strongest possible case for inferring these processes. Our review of the literature in early childhood emotional development focuses on studies of temperament, studies of parent-child interaction, and studies of the early development of emotional self-regulation. In these studies we find implicit and explicit definitions of emotion regulation and methods for distinguishing inferred emotion from inferred emotion regulation. These studies used a variety of methods that seemed fruitful for inferring emotion regulation, including temporal analyses of relations between emotion and regulatory phenomena, use of contrasting conditions, and differential patterns of converging multiple measures. Although temporal analyses provided the clearest evidence of emotion regulation, interpretations cannot assume a linear relation between emotion and emotion regulation.

Emotions are powerful, elusive, dynamic processes. They have the capacity to regulate other processes and to be regulated. These qualities present both great scientific challenges and the essence of what makes emotion regulation an exciting lens through which to study development. For emotion regulation research to achieve its goals, future studies need to frame their efforts conceptually and use methods that provide compelling inferential evidence. In this article we do not exhaust all the methods that can be used. We anticipate other developmental scientists will join in the effort to increase the rigor with which emotion regulation is studied. All of our research will benefit from such efforts. Ultimately, it is not the mere fact that humans are capable of emotion but how emotions are harnessed in the service of goals that will enlighten our understanding of developmental pathways.

\section{References}

Arnold, M. (1960). Emotion and personality. Vol. 1 Psychological aspects. New York: Columbia University Press.

Bakeman, R. (1997). Observing interaction: An introduction to sequential analysis. New York: Cambridge University Press.

Barrett, K. C., \& Campos, J. J. (1987). Perspectives on emotional development II: A functionalist approach to emotions. In J. D. Osofsky (Ed.), Handbook of infant development (2nd ed., pp. 555-578). New York: Wiley.

Bradley, S. J. (2000). Affect regulation and the development of psychopathology. New York: Guilford Press.

Braungart-Rieker, J., Garwood, M. M., Powers, B. P., \& Notaro, P. C. (1998). Infant affect and affect regulation during the still-face paradigm with mothers and fathers: The role of infant characteristics and parental sensitivity. Developmental Psychology, 34, 1428-1437.

Buss, K. A., \& Goldsmith, H. H. (1998). Fear and anger regulation in infancy: Effects of the temporal dynamics of affective expression. Child Development, 69, 359-374.

Calkins, S. D., \& Dedmon, S. E. (2000). Physiological and behavioral regulation in two-year-old children with aggressive/destructive behavior problems. Journal of $A b$ normal Child Psychology, 28, 103-118.

Calkins, S. D., Dedmon, S. E., Gill, K. L., Lomax, L. E., \& Johnson, L. M. (2002). Frustration in infancy: Implications for emotion regulation, physiological processes, and temperament. Infancy, 3, 175-197.

Calkins, S. D., Fox, N. A., \& Marshall, T. R. (1996). Behavioral and physiological antecedents of inhibited and uninhibited behavior. Child Development, 67, $523-540$.

Calkins, S. D., \& Johnson, M. C. (1998). Toddler regulation of distress to frustrating events: Temperamental and maternal correlates. Infant Behavior and Development, 21, 379-395.

Campos, J. J., Mumme, D. L., Kermoian, R., \& Campos, R. G. (1994). A functionalist perspective on the nature of emotion. In N. A. Fox (Ed.), The development of emotion regulation: Biological and behavioral considerations. Monographs of the Society for Research in Child Development, 59(2-3, Serial No. 240), 284-303.

Carstensen, L. L., \& Charles, S. T. (1998). Emotion in the second half of life. Current Directions in Psychological Science, 7, 144-149.

Casey, R. J. (1996). Emotional competence in children with externalizing and internalizing disorders. In M. Lewis \& M. W. Sullivan (Eds.), Emotional development in atypical children (pp. 161-183). Mahwah, NJ: Erlbaum.

Cicchetti, D., Ackerman, B. P., \& Izard, C. E. (1995). Emotions and emotion regulation in developmental psychopathology. Development and Psychopathology, 7, 1-10.

Cicchetti, D., Ganiban, J., \& Barrett, D. (1991). Contributions from the study of high-risk populations to understanding the development of emotion regulation. In J. Garber \& K. A. Dodge (Eds.), The development of emotion regulation and dysregulation (pp. 15-48). New York: Cambridge University Press. 
Cohn, J. F., \& Tronick, E. Z. (1988). Mother-infant face-toface interaction: Influence is bi-directional and unrelated to periodic cycles in either partner's behavior. Developmental Psychology, 24, 386-392.

Cole, P. M. (1986). Children's spontaneous control of facial expression. Child Development, 57, 1309-1321.

Cole, P. M., Jenkins, P. A., \& Shott, C. T. (1989). Spontaneous expressive control in blind and sighted children. Child Development, 60, 683-688.

Cole, P. M., Michel, M. K., \& Teti, L. O. (1994). The development of emotion regulation and dysregulation: A clinical perspective. In N. A. Fox (Ed.), The development of emotion regulation: Biological and behavioral considerations. Monographs of the Society for Research in Child Development, 59(2-3, Serial No. 240), 73-100.

Cole, P. M., Teti, L. O., \& Zahn-Waxler, C. (2003). Mutual emotion regulation and the stability of conduct problems between preschool and early school age. Development and Psychopathology, 15, 1-18.

Cole, P. M., Zahn-Waxler, C., \& Smith, K. D. (1994). Expressive control during a disappointment: Variations related to preschoolers' behavior problems. Developmental Psychology, 30, 835-846.

Davidson, R. J. (1985). Affect, cognition, and hemispheric specialization. In C. E. Izard, J. Kagan, \& R. B. Zajonc (Eds.), Emotion, cognition and behavior (pp. 320-365). Cambridge, England: Cambridge University Press.

Davidson, R. J., Jackson, D. C., \& Kalin, N. H. (2000). Emotion, plasticity, context, and regulation: Perspectives from affective neuroscience. Psychological Bulletin, 126, 890-909.

Davis, T. L. (1995). Gender differences in masking negative emotions: Ability or motivation? Developmental Psychology, 31, 660-667.

Denham, S. (1993). Maternal emotional responsiveness and toddlers' social-emotional competence. Journal of Child Psychology and Psychiatry, 34, 715-728.

Denham, S. (1998). Emotional development in young children. New York: Guilford Press.

Diener, M. L., \& Mangelsdorf, S. C. (1999). Behavioral strategies for emotion regulation in toddlers: Associations with maternal involvement and emotional expressions. Infant Behavior and Development, 22, 569-583.

Dodge, K. A. (Ed.). (1989). Coordinating responses to aversive stimuli: Introduction to a special section on the development of emotion regulation [Special issue]. Developmental Psychology, 25, 339-342.

Dumas, J. E., LaFreniere, P. J., \& Serketich, W. J. (1995). "Balance of power": A transactional analysis of control in mother-child dyads involving socially competent, aggressive, and anxious children. Journal of Abnormal Psychology, 104, 104-113.

Eisenberg, N. (2001). The core and correlates of affective social competence. Social Development, 10, 120-124.

Eisenberg, N., \& Fabes, R. A. (1992). Emotion and its regulation in early development. San Francisco: Jossey-Bass.

Eisenberg, N., \& Moore, B. S. (1997). Emotional regulation and development [Special issue]. Motivation and Emotion, 21, 1-6.
Feldman, R., Greenbaum, C. W., \& Yirmiya, N. (1999). Mother-infant affect synchrony as an antecedent of the emergence of self-control. Developmental Psychology, 35, $223-231$.

Field, T. (1994). The effects of mother's physical and emotional unavailability on emotion regulation. In N. A. Fox (Ed.), The development of emotion regulation: Biological and behavioral considerations. Monographs of the Society for Research in Child Development, 59(2-3, Serial No. 240), 208-227.

Field, T., \& Fogel, A. (Eds.). (1982). Emotion and early interaction. Hillsdale, NJ: Erlbaum.

Field, T., Healy, B., Goldstein, S., \& Guthertz, M. (1990). Behavior-state matching and synchrony in motherinfant interactions of nondepressed versus depressed dyads. Developmental Psychology, 26, 7-14.

Fisher, C. D., \& Ashkanasy, N. M. (2000). The emerging role of emotions in work life: An introduction. Journal of Organizational Behavior, 21, 123-129.

Fogel, A. (1993). Developing through relationships: Origins of communication, self, and culture. Chicago: University of Chicago Press.

Fox, N. A. (1994). Dynamic cerebral processes underlying emotion regulation. In N. A. Fox (Ed.), The development of emotion regulation: Biological and behavioral considerations. Monographs of the Society for Research in Child Development, 59(2-3, Serial No. 240), 152-166.

Fox, N. A., Rubin, K. H., Calkins, S. D., Marshall, T. R., Coplan, R. J., \& Porges, S. W., et al. (1995). Frontal activation asymmetry and social competence at four years of age. Child Development, 66, 1770-1784.

Frijda, N. H. (1986). The emotions. New York: Cambridge University Press.

Garber, J., \& Dodge, K. A. (1991). The development of emotion regulation and dysregulation. New York: Cambridge University Press.

Garner, P. W., \& Power, T. G. (1996). Preschoolers' emotional control in the disappointment paradigm and its relation to temperament, emotional knowledge, and family expressiveness. Child Development, 67, 1406-1419.

Gianino, A., \& Tronick, E. Z. (1988). The mutual regulation model: The infant's self and interactive regulation and coping defense capacities. In T. Field, P. McCabe, \& N. Schneiderman (Eds.), Stress and coping across development (pp. 47-68). Hillsdale, NJ: Erlbaum.

Giardino, N. D., Lehrer, P. M., \& Feldman, J. M. (2000). The role of oscillations in self-regulation: Their contribution to homeostasis. In D. T. Kenny \& J. G. Carlson (Eds.), Stress and health: Research and clinical implications (pp. 27-51). Amsterdam, Netherlands: Harwood Academic.

Gilliom, M., Shaw, D. S., Beck, J. E., Schonberg, M. A., \& Lukon, J. L. (2002). Anger regulation in disadvantaged preschool boys: Strategies, antecedents, and the development of self-control. Developmental Psychology, 38, $222-235$.

Goldsmith, H. H., Buss, A. H., Plomin, R., Rothbart, M. K., Thomas, A., \& Chess, S. (1987). What is temperament? Four approaches. Child Development, 58, 505-529. 
Gottman, J. M. (1994). What predicts divorce? Hillsdale, NJ: Erlbaum.

Grandey, A. A. (2000). Emotional regulation in the workplace: A new way to conceptualize emotional labor. Journal of Occupational Health Psychology, 5, 95-110.

Grolnick, W. S., Bridges, L. J., \& Connell, J. P. (1996). Emotion regulation in two-year-olds: Strategies and emotional expression in four contexts. Child Development, 67, 928-941.

Gross, J. J. (1998). The emerging field of emotion regulation: An integrative review. Review of General Psychology, 2, 271-299.

Gross, J. J., \& Munoz, R. F. (1995). Emotion regulation and mental health. Clinical Psychology: Science and Practice, 2, $151-164$.

Hanin, Y. L. (2000). Emotions in sport. Champaign, IL: Human Kinetics.

Harman, C., Rothbart, M. K., \& Posner, M. I. (1997). Distress and attention interactions in early infancy. Motivation \& Emotion, 21, 27-43.

Haviland-Jones, J. M., \& Kahlbaugh, P. (2000). Emotion and identity. In M. Lewis \& J. M. Haviland-Jones (Eds.), Handbook of emotions (2nd ed., pp. 293-305). New York: Guilford Press.

Izard, C. E. (1977). Human emotions. New York: Plenum Press.

Izard, C. E., \& Ackerman, B. P. (2000). Motivational, organizational, and regulatory functions of discrete emotions. In M. Lewis \& J. M. Haviland-Jones (Eds.), Handbook of emotions (2nd ed., pp. 253-264). New York: Guilford Press.

Josephs, I. E. (1994). Display rule behavior and understanding in preschool children. Journal of Nonverbal Behavior, 18, 301-326.

Kagan, J. (1994). On the nature of emotion. In N. A. Fox (Ed.), The development of emotion regulation: Biological and behavioral considerations. Monographs of the Society for Research in Child Development, 59(2-3, Serial No. 240), 7-24.

Kagan, J. (1999). The concept of behavioral inhibition. In L. A. Schmidt \& J. Schulkin (Eds.), Extreme fear, shyness, and social phobia: Origins, biological mechanisms, and clinical outcomes. Series in affective science (pp. 3-13). New York: Oxford University Press.

Kagan, J., Snidman, N., \& Arcus, D. (1993). On the temperamental categories of inhibited and uninhibited children. In K. H. Rubin \& J. B. Asendorph (Eds.), Social withdrawal, inhibition, and shyness in childhood (pp. 19-28). Hillsdale, NJ: Erlbaum.

Keenan, K. (2000). Emotion dysregulation as a risk factor for child psychopathology. Clinical Psychology: Science and Practice, 7, 418-434.

Kinsbourne, M. (1982). Hemispheric specialization and the growth of human understanding. American Psychologist, $37,411-420$.

Kobak, R. R., Cole, H. E., Ferenz-Gillies, R., \& Fleming, W. S. (1993). Attachment and emotion regulation during mother-teen problem-solving: A control theory analysis. Child Development, 64, 231-245.
Kopp, C. B. (1989). Regulation of distresses and negative emotions: A developmental view. Developmental Psychology, 25, 343-354.

Kopp, C. B., \& Neufeld, S. J. (2003). Emotional development during infancy. In R. J. Davidson, K. R. Scherer, \& H. H. Goldsmith (Eds.), Handbook of affective sciences (pp. 347-374). New York: Oxford University Press.

Lamb, M. E., \& Malkin, C. M. (1986). The development of social expectations in distress-relief sequences: A longitudinal study. International Journal of Behavioral Development, 9, 235-249.

Lazarus, R. S. (1991). Emotion and adaptation. New York: Oxford University Press.

Magai, C., \& Cohen, C. I. (1998). Attachment style and emotion regulation in dementia patients and their relation to caregiver burden. Journals of Gerontology: Series B: Psychological Sciences and Social Sciences, 53B, P147-P154.

Mangelsdorf, S. C., Shapiro, J. R., \& Marzolf, D. (1995). Developmental and temperamental differences in emotional regulation in infancy. Child Development, 66, 1817-1828.

Maughan, A., \& Cicchetti, D. (2002). The impact of child maltreatment and interadult violence on children's emotion regulation abilities. Child Development, 73, 1525-1542.

McEwen, B. S., \& Seeman, T. (1999). Protective and damaging effects of mediators of stress: Elaborating and testing the concepts of allostasis and allostatic load. In N. E. Adler, M. Marmot, B. S. McEwen, \& J. Stewart (Eds.), Socioeconomic status and health in industrial nations: Social, psychological, and biological pathways (pp. 30-47). New York: New York Academy of Sciences.

Porges, S. W., Doussard-Roosevelt, J. A., \& Maiti, A. K. (1994). Vagal tone and the physiological regulation of emotion. In N. A. Fox (Ed.), The development of emotion regulation: Biological and behavioral considerations. Monographs of the Society for Research in Child Development, 59(2-3, Serial No. 240), 167-186.

Rothbart, M. K., \& Bates, J. E. (1998). Temperament. In N. Eisenberg (Ed.) \& W. Damon (Series Ed.), Handbook of child psychology: Vol.3. Social, emotional, and personality development (5th ed., pp. 105-176). Mahwah, NJ: Erlbaum.

Rothbart, M. K., \& Derryberry, D. (1981). Development of individual differences in temperament. In M. E. Lamb \& A. L. Brown (Eds.), Advances in developmental psychology (Vol. 1, pp. 37-86). Hillsdale, NJ: Erlbaum.

Rothbart, M. K., Ziaie, H., \& O'Boyle, C. G. (1992). Selfregulation and emotion in infancy. In N. Eisenberg \& R. A. Fabes (Eds.), Emotion and its regulation in early development (pp. 7-24). San Francisco: Jossey-Bass.

Rutter, M. (1991). Age changes in depressive disorders: Some developmental considerations. In J. Garber \& K. A. Dodge (Eds.), The development of emotion regulation and dysregulation (pp. 273-300). New York: Cambridge University Press.

Saarni, C. (1984). An observational study of children's attempts to monitor their expressive behavior. Child Development, 55, 1504-1513.

Saarni, C. (1999). The development of emotional competence. New York: Guilford Press. 
Sackett, G. P. (1987). Analysis of sequential social interaction data: Some issues, recent developments, and casual inference model. In J. D. Osofsky (Ed.), Handbook of infant development (2nd ed., pp. 855-878). New York: Wiley.

Scherer, K. R., Schorr, A., \& Johnstone, T. (Eds.). (2001). Appraisal processes in emotion: Theory, methods, and research. New York: Oxford University Press.

Schmidt, L. A., Fox, N. A., Schulkin, J., \& Gold, P. W. (1999). Behavioral and psychophysiological correlates of selfpresentation in temperamentally shy children. Developmental Psychobiology, 35, 119-135.

Schore, A. N. (1994). Affect regulation and the origin of the self: The neurobiology of emotional development. Hillsdale, NJ: Erlbaum.

Shields, A., \& Cicchetti, D. (1997). Emotion regulation among school-age children: The development and validation of a new criterion Q-sort scale. Developmental Psychology, 33, 906-916.

Sroufe, L. A. (1996). Emotional development: The organization of emotional life in the early years. New York: Cambridge University Press.

Stack, D. M., \& Muir, D. W. (1990). Tactile stimulation as a component of social interchange: New interpretations for the still-face effect. British Journal of Developmental Psychology, 8, 131-145.

Stack, D. M., \& Muir, D. W. (1992). Adult tactile stimulation during face-to-face interactions modulates five-month olds' affect and attention. Child Development, 63, $1509-1525$.

Stansbury, K., \& Gunnar, M. R. (1994). Adrenocortical activity and emotion regulation. In N. A. Fox (Ed.), The development of emotion regulation: Biological and behavioral considerations. Monographs of the Society for Research in Child Development, 59(2-3, Serial No. 240), $108-134$.

Stern, D. N. (1977). The first relationship. Cambridge, MA: Harvard University Press.

Stern, D. N. (1985). The interpersonal world of the infant: A view from psychoanalysis and developmental psychology. New York: Basic Books.

Stifter, C. A. (2002). Individual differences in emotion regulation in infancy: A thematic collection. Infancy, 3, $129-132$.

Stifter, C. A., \& Braungart, J. M. (1995). The regulation of negative reactivity in infancy: Function and development. Developmental Psychology, 31, 448-455.

Stifter, C. A., Spinrad, T. L., \& Braungart-Rieker, J. M. (1999). Toward a developmental model of child compliance: The role of emotion regulation in infancy. Child Development, 70, 21-32.

Thompson, R. A. (1990). Emotion and self-regulation. In R. A. Thompson (Ed.), Nebraska Symposium on Motivation, 1988: Socioemotional development. Current theory and research in motivation (Vol. 36, pp. 367-467). Lincoln: University of Nebraska Press.
Thompson, R. A. (1994). Emotion regulation: In search of definition. In N. A. Fox (Ed.), The development of emotion regulation: Biological and behavioral considerations. Monographs of the Society for Research in Child Development, 59(2-3, Serial No. 240), 25-52.

Thompson, R. A., \& Calkins, S. D. (1996). The doubleedged sword: Emotional regulation for children at risk. Development and Psychopathology, 8, 163-182.

Tomkins, S. (1962). Affect, imagery, consciousness: Vol. 1. The positive affects. Berlin: Springer.

Tomkins, S. (1991). Affect, imagery, consciousness: Vol. 3. The negative affects: Anger and fear. New York: Springer.

Trevarthen, C. (1984). Brain science and the human spirit. In J. B. Ashbrook (Ed.), Brain, culture, $\mathcal{E}$ the human spirit: Essays from an emergent evolutionary perspective (pp. 129181). Lanham, MD: University Press of America.

Tronick, E. Z. (1989). Emotions and emotional communication in infants. American Psychologist, 44, 112-119.

Tronick, E. Z., Als, H., Adamson, L., Wise, S., \& Brazelton, T. B. (1978). The infant's response to entrapment between contradictory messages in face-to-face interaction. Journal of Child Psychiatry, 17, 1-13.

Tronick, E. Z., \& Cohn, J. F. (1989). Infant-mother face-toface interaction: Age and gender differences in coordination and the occurrence of miscoordination. Child Development, 60, 85-92.

Underwood, M. K. (1997). Top ten pressing questions about the development of emotion regulation. Motivation and Emotion, 21, 127-146.

Walden, T. A., \& Smith, M. C. (1997). Emotion regulation. Motivation and Emotion, 21, 7-25.

Weinberg, M. K., \& Tronick, E. Z. (1994). Beyond the face: An empirical study of infant affective configurations of facial, vocal, gestural, and regulatory behaviors. Child Development, 65, 1503-1515.

Weinberg, M. K., \& Tronick, E. Z. (1996). Infant affective reactions to the resumption of maternal interaction after the still-face. Child Development, 67, 905-914.

Weinberg, K. M., Tronick, E. Z., Cohn, J. F., \& Olson, K. L. (1999). Gender differences in emotional expressivity and self-regulation during early infancy. Developmental Psychology, 35, 175-188.

Wiggins, C., Cohen, L., Gitter, A., Zalewski, M., \& Cole, P. M. (2003, April). When anger organizes adaptive behavior: A view from the locked box. Poster presented at the biennial meeting of the Society for Research in Child Development, Tampa, FL.

Witherington, D. C., Campos, J. J., \& Hertenstein, M. J. (2001). Principles of emotion and its development in infancy. In G. Bremner \& A. Fogel (Eds.), Handbook of developmental psychology (pp. 427-464). Malden, MA: Blackwell.

Zimmerman, P. (1999). Structure and functions of internal working models of attachment and their role for emotion regulation. Attachment and Human Development, 1, 291-306. 
This document is a scanned copy of a printed document. No warranty is given about the accuracy of the copy. Users should refer to the original published version of the material. 